\title{
O Legado de MaQuiaVEL No teatro de Luigi Pirandello
}

\section{Priscila Nogueira da Rocha e Sonia Cristina Reis*}

RESUMO: O presente artigo pretende analisar as obras Mandragola (1518), de Nicolau Maquiavel, e L'uomo, la bestia e la virtù (1919), de Luigi Pirandello, buscando evidenciar que, embora em séculos diferentes, os textos dos dramaturgos facultam um diálogo no que tange à utilização do recurso de máscaras sociais para encobrir seu real interesse, como, por exemplo, na figura do astuto, que usa uma poção na tentativa de ajudar a personagem principal a resolver seus problemas, e no emprego do riso como recurso estilístico. Assim como na obra de Maquiavel, é possível encontrar no texto de Pirandello uma sátira sobre a Itália de sua época, indicando uma série de hábitos de sua sociedade e, tal como Lucrezia na obra de Maquiavel, a Sra. Perella da obra de Pirandello disfarça sua traição e, mediante o riso (ou mais especificamente o riso humorístico), o autor siciliano direciona o público a perceber que, independente da época, manter as aparências é mais relevante para a manutenção do status social do que a essência e a virtude.

PALAVRAS-CHAVE: Maquiavel; Pirandello; Teatro italiano; Comédia.

ABSTRACT: Quest'articolo intende analizzare le opere Mandragola (1518), di Niccolò Machiavelli, e L'uomo, la bestia e la virtù (1919), di Luigi Pirandello, cercando di evidenziare che, nonostante siano state prodotte in secoli diversi, i testi consentono/provocano un dialogo che riguarda l'uso delle maschere sociali per celare il reale interesse dei protagonisti, come per esempio nella figura dell'astuto, il quale usa una pozione nel tentativo di aiutare il personaggio principale/il protagonista a risolvere $\mathrm{i}$ suoi problemi e l'uso del riso come risorsa stilistica. Come nell'opera di Machiavelli, è possibile trovare nel testo di Pirandello una satira sull'Italia del suo tempo, indicando una serie di abitudini di quella società e, come Lucrezia nell'opera di Machiavelli, la signora Perella di Pirandello riesce a dissimulare il suo tradimento attraverso il riso (o più specificamente il riso umoristico), l'autore siciliano indirizza il pubblico a rendersi conto che, indipendentemente dall'epoca trattata, mantenere le apparenze è più rilevante per conservare lo status sociale dell'essenza e della virtù.

PAROLE-CHIAVE: Machiavelli; Pirandello; Teatro italiano; Commedia. 
ABSTRACT: This article intends to analyze the works of Mandragola (1518) by Nicolau Machiavelli and Luigi Pirandello's L'uomo, la bestia e la virtù (1919), seeking to show that, although in different centuries, the writings of playwrights allow a dialogue in which refers to the use of social masks to cover up his real interest, for example in the figure of the cunning, who uses a potion in an attempt to help the main character solve his problems, and in the use of laughter as a stylistic resource. As in Machiavelli's work, it is possible to find in the text of Pirandello a satire about the Italy of his time, indicating a series of habits of his society and, like Lucrezia in the work of Machiavelli, Pirandello's Mrs. Perella disguises his betrayal, and through laughter (or more specifically humorous laughter), the sicilian author directs the public to realize that, regardless of the age, maintaining appearances is more relevant to the maintenance of social status than essence and virtue.

KEYWORDS: Machiavelli; Pirandello; Italian Theater; Comedy. 


\section{O Autor e o Teatro}

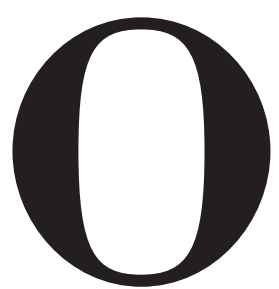

nome de Luigi Pirandello (1867-1936), embora autor de significativo conjunto de romances e poesias, tem no teatro sua maior contribuição, sendo considerado um dos grandes renovadores da segunda arte, apresentando em suas obras questionamentos críticos à realidade de sua época. Acredita-se que Pirandello, além da aparente preferência pelo teatro, buscasse uma nova forma para tratar de assuntos que sempre estrelaram suas obras, como o mascaramento social, as personalidades multifacetadas de seus personagens, a hipocrisia das relações interpessoais, o engano, dentre outros. Podemos pensar ainda que a escolha do teatro lhe permitiria alcançar dimensões, objetivos e público diferentes daqueles da escrita narrativa.

É possível encontrar em seus textos referências a comédias clássicas latinas e aos textos de Maquiavel, como se verifica em correspondência de 18 de agosto de 1887:

(...) Ieri sera con moltissimo mio piacere, sono stato a sentire al Bellini la Mandragola di Niccolò Machiavelli, decor nostro! Mi sentivo trasportato in pieno secolo XVI, secolo d'oro della nostra letteratura. Fui più d'una volta in procinto di dare una ceffata a vari spettatori 'retini e imbecilli che si permettevano di non rispettare il silenzio. Alla volta ventura se avrò più spazio vi trascriverò due ballate del mio Belfagor (NARDELLI, 1962).

Este trecho faz referência a duas obras de Maquiavel, embora no caso de Belfagor, a única novela de Maquiavel, se refira a sua própria versão da obra, poema escrito em prosa e verso, em 1886, que o dramaturgo siciliano tinha reelaborado. Nela, Moriconi (2014) pôde verificar alguns elementos novos na obra pirandelliana, como exemplifica o primeiro canto, detalhando minuciosamente o processo de transformação de Belfagor de demônio em homem que, embora não pudesse apresentar sua essência diabólica, seria capaz de sobreviver por conta própria neste mundo. Outra novidade surge ainda na primeira parte, La visita, que narra o encontro do narrador com Belfagor que, deixando momentaneamente o seu submundo, se apresenta no quarto de Pirandello em contexto mais narrativo e realístico, promovendo um envolvimento direto do escritor com o personagem. Zangrini (1994) explicita que, embora ambas as obras tratem da mulher e proponham que o verdadeiro inferno seja viver na Terra, o texto pirandelliano traz 
uma interpretação misógina que não existia em seu antecessor.

Tendo, portanto, sido encontrados indícios que revelam Pirandello leitor e influenciado pela escrita de Maquiavel, pretendemos investigar os fatores que apontam para a influência da obra teatral Mandragola (1514), na peça L'uomo, la bestia e la virtù (1919). É importante salientar que Pirandello, fiando a análise menos na forma e mais na maneira de transmitir sua visão ao espectador, utiliza o humor pautado na ironia, dando sempre atenção aos absurdos das relações cotidianas. E a influência maquiaveliana não é sentida apenas nas duas obras citadas: também Liolá (1916) apresenta características que repercutem o autor florentino, porém, neste artigo, nos restringiremos à obra supracitada.

Para corroborar com a ideia da influência maquiaveliana nas obras de Pirandello, podemos partir da afirmação em que o autor defende Maquiavel como um dos humoristas italianos a serem reconhecidos:

Ed io pensavo alla grandezza nuda di questo Sommo nostro, che non andò mai a vestirsi nel guardaroba della retorica; che come pochi comprese la forza delle cose; a cui la logica venne sempre dai fatti; che contro ogni sintesi confusa reagì con l'analisi più arguta e più sottile; che ogni macchina ideale smontò coi due strumenti dell'esperienza e del discorso; che ogni esagerazione di forma distrusse col riso; pensavo che nessuno ebbe maggiore intimità di stile di lui e più acuto spirito d'osservazione; che poche anime furono come la sua disposte all'apprensione dei contrasti, a ricevere più profondamente l'impressione delle incongruenze della vita (PIRANDELLO, 1993).

\section{L'uomo, la bestia e la virtù}

Perché civile, esser civile, vuol dire proprio questo: dentro, neri come corvi; fuori, bianchi come colombi; in corpo fiele; in bocca miele.

(Luigi Pirandello, "L'uomo, la bestia e la virtù").

Comédia teatral ou, nas palavras de Pirandello, um apólogo ${ }^{1}$ em três atos. Definida pelos especialistas como uma sátira amarga, sua leitura permite inferir que o homem é também a besta. Maquiavel em seu Il Principe escreve: "ad uno principe è necessario saper usare la bestia e l'uomo" (Il Principe, cap XVIII), podendo a besta, segundo ele, ser uma raposa ou um leão; de fato, na obra de Pirandello, o personagem Sr. Paolino se transforma em raposa para sujeitar o leão. Acredita-se que o autor tenha usado esta referência de Maquiavel para dar título a sua peça, cuja trama ${ }^{2}$ é ambientada em uma cidade marítima e gira em torno da Senhora Perella, casada com um capitão que passa longos períodos viajando, e de seu amante, o professor Paolino. Ao descobrirem a gravidez de Perella, às vésperas da chegada do capitão, os amantes articulam um plano: como todo retorno do marido resulta em briga e uma noite em quartos separados, Paolino colocaria um afrodisíaco na torta ofertada ao capitão, para garantir

1 O dicionário Treccani define apólogo como sinônimo de fábula. Acredita-se que a opção de Pirandello pela fábula seria uma citação/homenagem a Maquiavel e sua Mandragola.

2 A peça L'uomo, la bestia e la virtù é uma transposição, e retoma fielmente a trama da novela Richiamo all'obbligo (1906), do mesmo autor. Mais uma vez, acredita-se que a transposição à forma teatral seria uma homenagem ao teatro de Maquiavel. 
que passasse a noite junto da esposa, justificando a gravidez imprevista. Na esperança de que algo acontecesse, tendo o capitão comido a torta, Paolino volta para casa pedindo à Sra. Perella que deixasse um jarro de flores na janela como sinal de sucesso. No dia seguinte não vê o vaso e se desespera, descobrindo só depois que tudo correra conforme o planejado.

A comédia é considerada grotesca devido, principalmente, à descrição de alguns personagens. De acordo com as didascálias ${ }^{3}$, alguns deles deveriam ser maquiados, visando se assemelharem a animais, como a governanta do Sr. Paolino (que deveria parecer uma galinha), o farmacêutico (raposa), os estudantes do início da obra (cabra e macaco de óculos), Nonò (filho do casal, como um gato) e o Capitão Perella (javali). Isso contribui para a ideia do grotesco, porém não só isso: dão à história um tom de fábula, declarado, também, no prólogo de Mandragola ${ }^{4}$. Outro resultado da estética animalesca é a arquetipificação que dela advém: de modo análogo aos cargos sociais (padre, parasita, burguês, senhor das leis, etc.) dos personagens maquiavelianos, que lhes serviam de introdução, aqui são os animais que previnem o espectador quanto às especificidades de cada personagem.

Já no título da obra se apresentam três modelos morais: o homem, ligado ao Professor Paolino, honesto e respeitável; a besta, no violento e genioso Capitão Perella; e a virtude, na figura da Sra. Perella, negligenciada pelo marido e grávida do amante que, para salvar sua honra de mulher virtuosa, precisa se relacionar com seu marido que, porém, tendo outra família, não a deseja, fazendo necessário o afrodisíaco. Na novela que dá origem à peça, o símbolo que evidenciaria a reparação da virtude da esposa era um lenço, enquanto na versão teatral a simbologia muda para vasos de flor-de-lis ${ }^{4}$, surgindo no dia seguinte não um, mas cinco vasos:

Paolino Ma di tutte le bestialità che poc'anzi mi sono scappate di bocca! Ero così nervoso! Ma è stato uno sfogo, che mi ha tanto giovato! M'è passato tutto... Sono contento ora... tanto contento... Mi scusi e grazie, grazie, signor capitano! Con tutto il cuore! Guardi, là... che azzurro... che bella giornata s'è fatta! e quei... con stupore che è quasi terrore uh! cinque, cinque vasi là!

Signora Perella (che ha il quinto vaso tra le mani, che contiene il giglio, mostrandolo, vergognosa, con gli occhi bassi) Ridanno la vita.

\section{(Cena 4, ato 3)}

Esta mudança permite a inserção de um traço de humor erótico quando a Sra. Perella, carregando o quinto vaso de flor-de-lis (de forma notadamente fálica), diz em sua última fala: "Ridanno la vita", ao que segue a fala do Capitão: "Eh, caro professore, bisogna essere uomini!” (para sustentar uma família5), e termina com Paolino: “A lei è facile, capitano con una signora come la sua: la Virtù in persona!” parecendo, superficialmente, uma contradição. Entretanto, uma análise um pouco mais detida permite entrever a expressão de uma

3 Didascálias ou indicações cênicas: Rubricas ou indicações cênicas, segundo Pavis, significa "todo texto não pronunciado pelos atores e destinado a esclarecer ao leitor a compreensão ou o modo de apresentação da peça. Por exemplo: nome das personagens, indicações das entradas e saídas, descrição dos lugares, anotações para a interpretação, etc." (PAVIS, 2003 p. 206)

$4 \quad$ Acredita-se que a escolha do vaso de flor-de-lis (ou lírios) como símbolo é uma homenagem a Maquiavel, uma vez que esta é a flor símbolo de sua Florença. A flor também simboliza a lealdade que Maquiavel sempre teve em relação a sua terra, apesar de suas pesadas críticas.

5 Estas falas ocorrem após um desabafo do professor ao capitão sobre sua preocupação em sustentar sua vindoura família (uma vez que até este momento acreditava que seu plano havia falhado). 
dose do humor de Pirandello, mostrando um Paolino dissimulado e imoral falando sobre a virtude de Sra. Perella, causando desconforto no público perante a situação de tê-la engravidado, mas estar aliviado pela resolução do problema, mostrando certa ironia em sua posição de amante, com toda a tensão e expectativa a que esteve sujeito. $\mathrm{O}$ tema do encontro erótico nestes modelos morais, apresentados de maneira cômica e organizados com base no engano, embora presente nas novelas de Boccaccio, inaugurou seu protagonismo em Mandragola, cuja trama central também se solucionava através de uma infusão mágica, ignorando obstáculos religiosos e morais de seu tempo. Aqui, a mudança aparece no comportamento da personagem Lucrezia, que é apresentada como jovem senhora casada e muito virtuosa, mas, embora seguidora dos ditames da igreja católica, ao final se torna adúltera, se aproveitando da oportunidade que a vida lhe oferecera, como evidenciado no trecho:

Poiché l'astuzia tua, la sciocchezza del mio marito, la semplicità di mia madre e la tristizia del mio confessore mi hanno condotto a fare quello che mai per me medesima avrei fatto, io voglio iudicare che venga da una celeste disposizione, che abbi voluto così, e non sono sufficiente a recusare quello che 'l Cielo vuole che io accetti. Però, io ti prendo per signore, patrone, guida: tu mio padre, tu mio defensore, e tu voglio che sia ogni mio bene; e quel che 'l mio marito ha voluto per una sera, voglio ch'egli abbia sempre. Farà ti adunque suo compare, e verrai questa mattina alla chiesa, e di quivi ne verrai a desinare con esso noi; e l'andare e lo stare starà a te, e potreno ad ogni ora e senza sospetto convenire insieme (Cena 4 , ato $\mathrm{V}$ ).

Nas duas obras encontramos um duplo sentido metafórico, levando ao entendimento de que o engano permite retomar a normalidade. Assim como em Mandragola, os três protagonistas de Pirandello alcançam seus objetivos, chegando a uma situação de equilíbrio. A dualidade deixa transparecer hipocrisia e cegueira social, em que a busca pelo outro, pelo próprio par, é construída por meio do contraste entre como a pessoa é e o modo como ela aparece. A obra de Pirandello difere, porém, no comportamento da sociedade, que aceita as máscaras de falsidade do marido traído e da mulher adúltera como um mal necessário, indispensável nas peças teatrais, onde cada um impõe ao outro a necessidade de normalizar o seu papel e apresentar uma imagem falsa, sempre hipócrita, para retomarem suas máscaras sociais e poderem aparecer de forma a esconder sua verdadeira realidade.

Guinsburg (1999, p. 12) assinala que Pirandello traça os contornos de sua "poética de criação", a fim de revelar as ambiguidades e ambivalências dos seres, bem como os caminhos da auto representação, e o autor coloca em cena:

[...] a pessoa como personae, como máscara de si mesma, como forma que define a sua personagem no jogo do ser não sendo do homem; a identidade que é ao mesmo tempo o velar-se da ficção para o revelar-se do real no irreal pelos atos de realização dramatúrgica da obra teatral. (GUINSBURG, 1999, p. 12) 
Pirandello mostra no texto a santidade da mãe e a torpeza do sexo. Enquanto está maquiando a Sra. Perella e pedindo para que ela seduza o marido para ele não perceber sua gravidez, revela que essa virtude não permanece igual a si mesma, e mostra uma mulher frustrada que aparece mais como objeto do que sujeito da ação, como uma marionete de Paolino, que a convence da culpa do marido (a besta) em não cumprir com os deveres conjugais, porém omitindo a própria traição, e para salvar sua virtude, deveria sujeitar-se ao marido, mantendo assim as aparências:

Paolino (intenerendosi fino alle lagrime, abbracciandola) Sì... sì... hai ragione, povera anima mia, sì! hai ragione! Ma che vuoi farci? Ti vuole lui, così. Non ti vuole madre! E tu la darai a lui, codesta maschera, alla sua bestialità! Sotto di essa, sei poi tu, che ne spasimi; tu come sei per te stessa e per me, cara! E tutto il nostro amore! (Cena 6, ato 2)

Interessante notar que, à medida que a obra se encaminha para o final, as máscaras vão sendo alteradas: o professor se transforma em besta, enquanto o rude capitão começa a mostrar seu lado mais humano, denotando que a hipocrisia e o oportunismo exaltam a dualidade do homem que, ao trocar de máscara, parafraseando o próprio autor, poderá ser "uno, nessuno, centomila".

\section{Riso e humorismo}

Outra referência ao que acontece em Maquiavel é o tipo de riso que o autor busca provocar nesta obra: apesar de comédia, ainda que em forma de apólogo, uma fábula, como o próprio autor diz ${ }^{6}$, o riso deriva do sofrimento, de uma amargura invencível, que extrai de si toda doçura e serenidade. $\mathrm{O}$ riso, por mais sincero que se suponha, esconde uma segunda intenção. Em Mandragola, o riso provocado por Maquiavel não tem caráter puramente cômico, pois vem da representação de um mundo de enganos, espelho do real, porém espiado por detrás do véu social, mostrando personagens que, se são intrinsecamente engraçados, expostos cruamente em seus desejos e sua intimidade, onde os escrúpulos e a moral não os alcançam, provocando em seus leitores/espectadores um riso incômodo e nervoso, derivado da identificação consigo e com os seus. O escárnio vem, portanto, da exposição das falhas daquela sociedade e dos indivíduos que a formam, retrato de um autor em profundo pessimismo, completamente desesperançoso nas virtudes humanas.

Pirandello, em O humorismo (1993), disserta sobre as contradições presentes na literatura que se apresentam como uma das bases para a identificação de traços humorísticos numa escrita:

Características mais comuns e, no entanto, mais geralmente observadas, são as contradições fundamentais às quais se costuma dar por causa principal o desacordo que o sentimento e a meditação descobrem, ou entre a vida real e o ideal humano, ou entre as nossas aspirações e

6 Retornando à influência de Maquiavel em sua obra, que na quarta estrofe começa com uma forma tipicamente terenciana, nomeando a obra: "La favola si chiama Mandragola: voi vedrete la causa nel recitar la, come io prevedo". Entretanto, percebe-se aqui, além da simples apresentação do nome da obra (e da referência a seu mestre, Terêncio), uma insinuação que vem plantada antes do início da história propriamente dita, chamando a atenção do espectador para uma segunda camada oculta pela fábula simples e popularesca, e é esta camada que conterá a substância do discurso crítico de Maquiavel à sociedade, demonstrando, por trás do verniz visível, todo o pessimismo e amargura do autor. Esta ótica permite entender a dupla natureza dos personagens, que dão vida a uma tragédia encoberta por uma comédia. Este mesmo tipo de texto será encontrado na obra de Pirandello. 
as nossas debilidades e misérias, e por principal efeito aquela tal perplexidade entre o pranto e o riso.

Croce (1990) define que o ato humorístico estará no riso entre as lágrimas, o riso amargo, o salto brusco do cômico para o trágico e vice versa. E define o cômico como "il dispiacere destato dalla percezione di una stortura e seguito subito da un maggior piacere derivante dal rilasciarsi delle nostre forze psichiche, che erano tese nell'aspettazione di qualcosa che si prevedeva importante" ${ }^{7}$. Terá, porém, a sua afirmação contestada por Pirandello, que defende não existirem nem cômico, nem humorismo, mas escritores cômicos e humoristas.

Para Pirandello o humorismo é um gênero literário dramático crucial, e diferencia o cômico do humor nas narrativas. O cômico, segundo ele, seria um "avvertimento del contrario", algo ou alguém que destoa do esperado, dando como exemplo a figura de uma velha senhora vestida e maquiada como uma mocinha. Pirandello, entretanto, convida seu leitor a avaliar mais profundamente a imagem, a pensar no que estaria por trás da aparência um tanto ridícula daquela senhora: o desejo de parecer mais jovem para o marido. A partir do instante em que se verificam os reais motivos, o riso perde o sentido e não há mais nada de engraçado na aparência daquela senhora. A reflexão crítica, portanto, desperta um sentimento distinto, o "sentimento do contrário", que constitui a base do humorismo pirandelliano:

Mas se agora em mim intervém a reflexão e me sugere que aquela velha senhora não sente talvez nenhum prazer em vestir-se como um papagaio, mas que talvez sofra por isso e o faz somente porque se engana piamente e pensa que, assim vestida, escondendo assim as rugas e as cãs, consegue reter o amor do marido, muito mais moço do que ela, eis que já não posso mais rir disso como antes, porque precisamente a reflexão, trabalhando dentro de mim, me leva a ultrapassar aquela primeira advertência, ou antes, a entrar mais em seu interior: daquele primeiro advertimento do contrário ela me faz passar a esse sentimento do contrário. E aqui está toda a diferença entre o cômico e o humorístico (PIRANDELLO, 2009, p. 147).

A leitura da obra de Pirandello permite entender onde entrariam o pranto e o riso. A contraposição de realidade e idealização se mostra mais evidente, e não se sabe qual seria a melhor solução para o problema: apresentar a verdade cruel, que exporia os personagens, ou o engano, a mentira que celebraria a situação. Pirandello apresenta um Sr. Perella que possui uma amante em outra cidade e trata com menosprezo sua família; por outro lado apresenta Paolino, supostamente boa pessoa, direcionando inicialmente seu espectador a torcer que nele a Sra. Perella encontre o amor verdadeiro, mas que no decorrer da narrativa se revela um homem covarde, egoísta e manipulador, apesar de seu sincero apreço pela senhora. Essas características também podem ser encontradas em Callimaco, protagonista de Mandragola, que mesmo desempenhando três papéis: jovem apaixonado, médico falso e malandro, se mostra no fundo um fraco, incapaz, indigno de dores ou alegrias. Rico e bonito, porém direcionado a coisas fúteis e vãs. É egoísta e incapaz de agir sozinho, tanto que recorre ao parasita Ligurio. Cada dificuldade lhe parece insustentável e muitos de seus lamentos invocam a própria morte.

B. CROCE, Estetica come scienza dell'espressione e linguistica generale. In G. GALASSO (ORG) Teoria e storia. Milano: Adelphi, 1990, p. 116. 
Pirandello apresenta um caráter crítico embutido na obra, com muitos questionamentos, mas conquista seu público com as situações arriscadas e engraçadas pelas quais passa o protagonista, pelo clima suspenso e pela apreensão causados pelo plano arquitetado por Paolino, pela riqueza de detalhes de cada personagem e como suas características psicológicas são desenvolvidas de maneira natural e agradável. Na tentativa de definir o humorismo, Pirandello afirma:

(...) se quiséssemos ter em conta todas as respostas que foram dadas a essa pergunta, de todas as definições que autores e críticos tentaram dar-lhe, poderíamos encher muitas e muitas páginas, e provavelmente ao fim, confusos entre tantos pareceres e contra-pareceres, não conseguiríamos outra coisa senão repetir a pergunta (...). (PIRANDELLO, 1999, p. 175)

mostrando que a multiplicidade de verdades está presente não só em suas obras, mas na própria conceituação do termo.

Em Mandragola pode-se afirmar que Maquiavel não enxerga a ação dos personagens - seja a tolice de Nicia, a cupidez de Callimaco ou a entrega de Lucrezia - com olhos moralistas. O que lhe importa é a compreensão e a representação da natureza humana de forma fidedigna, e por isso a comédia foi escolhida como meio ideal para alcançar os seus propósitos. Ao propor personagens comuns de sua cidade, ele os usa como exemplos para a condição humana, não denunciando a amoralidade de seu comportamento, mas expondo o engano e a hipocrisia dos que acreditam que podem moldar a vida dos homens segundo valores abstratos, que ancoram virtudes impossíveis de serem vividas plenamente. Para Maquiavel, os homens escondem desejos que nem mesmo as máscaras sociais podem suprimir. Sejam os letrados, os religiosos, as mulheres virtuosas, empregados e todos os cidadãos fazem parte de uma sociedade que se refugia nos ritos sociais para esconder seu lado mais obscuro. E sua Mandragola se mantém atual devido ao fato de reconhecer nos personagens uma parte da sociedade e da eterna comédia da vida privada. Já na obra L’uomo, la bestia e la virtù, as máscaras se multiplicam. Paolino ora é sincero, ora um grande mentiroso e manipulador, ora passional, ora racional. O próprio título da obra não esclarece quem seria o homem, a besta ou a virtude, e mesmo após a leitura, a dúvida permanece, sendo possível inferir que não haveria resposta definitiva, ou que todos teriam dentro de si um pouco de cada. Acredita-se, a partir do pensamento pirandelliano, que o autor buscava confundir o seu público com a pluralidade de significados e sentidos. Pirandello não acreditava numa verdade absoluta, ou numa realidade única. Não é possível encontrar na obra pirandelliana a presença de heróis, como também não era em Maquiavel. Os personagens são seres comuns, retirados de uma vida comum, em situações que, buscando uma verossimilhança, apesar dos absurdos, poderiam acontecer na rotina diária da sociedade. Ao observar as características de Paolino, nota-se que o autor propositadamente o distancia do perfil heroico. Ao contrário, seus personagens são incompletos, falhos, contraditórios em suas atitudes. Não se sabe se o personagem protagonista quer resolver o seu problema, salvar sua amante ou consertar a situação pela conclusão de um final feliz. Pirandello afirma no seu livro Humorismo (1993): 
Sim, um poeta épico ou dramático pode representar um herói seu. No qual se apresentam em luta elementos opostos e repugnantes; mas ele, com estes elementos, comporá um caráter e quererá torná-lo coerente em cada ato seu. Pois bem, o humorista faz realmente o inverso: ele decompõe o caráter em seus elementos, e enquanto aqueles procuram torná-lo coerente em cada ato, estes se divertem, então, em representá-lo nas suas incongruências. (PIRANDELLO, 1999, p. 175)

Bruni (2015), ao falar sobre a escrita de Pirandello, afirma que o autor dialoga com suas raízes sicilianas, mas grande parte com a literatura de base grega, romana e árabe e com Dante, Ariosto e Maquiavel. Lê em Maquiavel a dificuldade da sociedade de aprender uma língua que tenha seu próprio valor literário, e surgiria também em Maquiavel a superação da ironia em favor do humorismo na teatralidade cotidiana. A língua aparece como elemento central, sendo instrumento na caracterização dos personagens, formando um legado das palavras nos confrontos ao longo do tempo. A língua permanece identidade nacional em uma cultura que, a fim de viver sua empresa, precisa também tornar-se uma língua literária.

\section{Conclusão}

Ao fim desta análise, podemos entender que, ao optar pela aparente leveza da comédia, os autores puderam mostrar um discurso capaz de penetrar além das aparências, da ficção, para transformar-se em uma crítica de sua sociedade. O riso amargo compartilhado pelos autores provoca em seu público a sensação agridoce da identificação, da verossimilhança, do aparente absurdo representado em cena, inclusive quando da exposição cruel de suas próprias mazelas. A comédia teatral é o instrumento pelo qual Maquiavel destila sua crítica, representando sua sociedade e seus personagens como em um espelho, herança que seria revisitada séculos mais tarde na obra de Pirandello, deixando clara sua ampla influência e a atualidade de sua abordagem, ainda soberbamente relevante. 


\section{Referências}

CROCE, B., Estetica come scienza dell'espressione e linguistica generale. Teoria e storia, a cura di G. Galasso. Milano: Adelphi,1990.

BENTLEY, E. O Dramaturgo Como Pensador. Rio de Janeiro: Civilização Brasileira, 1991.

GUINSBURG, J. (org). Pirandello - do teatro no teatro. São Paulo: Perspectiva, 1999.

LA VOCE DI MARUGGIO. Nell'identità della lingua l'invisibile della presenza e dell'assenza: Pirandello nel gioco delle maschere. Disponível em <http://www.lavocedimaruggio.it/wp/nellidentitadella-lingua-linvisibile-della-presenza-e-dellassenza-pirandello-nel-gioco-delle-maschere.html>. Acesso em: 05 jul. 2017

MINOIS, Georges. História do riso e do escárnio. São Paulo: Editora UNESP, 2003.

MORICONI, B. Metamorfosi di un arcidiavolo: Il personaggio di Belfagor da Machiavelli a oggi. Napoli: Edizioni Scientifiche Italiane, 2013.

NARDELLI, F. Vita segreta di Pirandello. Roma: Vito Bianco, 1962.

PAOLUCCI, A. Theatre of illusion: Pirandello's Liolà and Machiavelli's Mandragola. Comparative literature studies, n. 9 (mar. 1972), p. 44-57.

PAVIS, Patrice. Dicionário de Teatro. São Paulo: Perspectiva, 2003.

PIRANDELLO, L. L'innesto - la patente - l'uomo, la bestia e la virtù. Milano: Mondadori, 1992.

PIRANDELLO. L'umorismo. In: Saggi, poesie, scritti varri. $5^{\text {a }}$ ed. Milano: Arnoldo Mondadori, 1993.

PIRANDELLO, Luigi. O Humorismo. In Pirandello - do teatro no teatro. São Paulo, Perspectiva, 1999.

ZANGRILLI, F. Lo specchio per la maschera: Il paesaggio in Pirandello. Disponível em https://www. jstor.org/stable/pdf/480094.pdf?refreqid=excelsior\%3Ad948e8815f4867ee57 5483d517d4749e>. Acesso em: 22 jun. 2017.

Recebido: $12 / 08 / 2019$

Aprovado: 11/11/2019 